\title{
Effects of Digital Storytelling in Mathematics Instruction on Academic Achievement and Examination of Teacher-Student Opinions on the Process $^{*}$
}

\author{
İlknur Özpinar ${ }^{1}$, Semirhan Gökçe ${ }^{2}$, Arzu Aydoğan Yenmez ${ }^{1}$ \\ ${ }^{1}$ Department of Mathematics and Science Education, Niğde Ömer Halisdemir University, Niğde, Turkey \\ ${ }^{2}$ Department of Computer Education and Instructional Technology, Niğde Ömer Halisdemir University Niğde, Turkey \\ Correspondence: İlknur Özpinar, Department of Mathematics and Science Education, Niğde Ömer Halisdemir \\ University, Niğde, Turkey.
}

Received: August 15, 2017

doi:10.11114/jets.v5i10.2595

\author{
Accepted: September 6, $2017 \quad$ Online Published: September 14, 2017 \\ URL: https://doi.org/10.11114/jets.v5i10.2595
}

\begin{abstract}
Storytelling is a popular instrument used in every domain of natural and social interaction for human communication and commonly used in classrooms to enrich the learning experience. With the use of technological tools in every field of our daily lives, its use in educational environments has become inevitable and in parallel with the development of these tools, digital stories have started to replace traditional storytelling. Digital storytelling offers advantages such as providing diverse applications in the classroom environment, personalizing the learning experience, being interesting, helping difficult subjects explained, addressing real-life-related situations, supporting active learning, allowing for the creation of costless learning environments, and improving motivation and achievement. Materializing a course such as mathematics in which abstract concepts are given, helping students use the learned information with stories and associate it with daily life, developing activities to make learning environments enjoyable when learning and applying by taking students away from the traditional understanding of instruction are considered some of the most important duties of teachers in this process. In accordance with the related considerations, this study aims to investigate the effects of mathematics courses instructed by association with digital storytelling on 8th-grade students' academic achievements and the teacher and student opinions on the application process. The study using the quasi-experimental method was conducted with 58 students. The Achievement Test, written opinion forms to receive student opinions and interview form for teacher were prepared by the researchers to this end. At the end of the study, although no statistically significant differences were found between the groups in the posttest and the delayed-posttest in terms of academic achievement score averages of the students in the experimental group were found to be higher than the score averages of the students in the control group. The results achieved in this study show that digital storytelling is a powerful instrument to create more interesting and enjoyable learning environments which facilitate association with daily life, allow for effective learning and participation. It was also stated that the students and the mathematics teacher had positive opinions on use of digital stories in the courses and its contribution to the courses.
\end{abstract}

Keywords: digital storytelling, mathematics instruction, academic achievement, teacher opinion, student opinion

\section{Introduction}

Storytelling is a natural way for individuals to communicate and present in all kinds of social interaction. Humans tend to narrate stories to tell complicated ideas, concepts or information in a better way when getting into interaction with others (Demirer, 2013; Xu, Park \& Baek, 2011). Individuals are liable to pay more attention to what is told when they face interesting and exciting stories (Gils, 2005). Hence, storytelling has been a crucial educational instrument to convey information from a generation to the next one since the early ages (Smeda, Dakich \& Sharda, 2014; Suwardy, Pan \& Seow, 2013; Wang \& Zhan, 2010). Storytelling is a simple but powerful instrument to explain complex, difficult and abstract subjects (Inan, 2015; Robin, 2006, 2008; Smeda, Dakich \& Sharda, 2014). It is accepted as a strong tool to enable the teaching and learning process to be more effective, meaningful, enjoyable and creative (Wang \& Zhan, 2010).

"Part of this study was orally presented in 6th Cyprus International Conference on Educational Research (CYICER-2017) (04-06 May 2017). 
The use of technological tools in every domain of our daily lives has also made it inevitable for them to be used in educational environments. In parallel with the development of these tools, digital stories have therefore replaced traditional storytelling (Condy, Chigona, Gachago \& Ivala, 2012). Digital storytelling is a process of creating a story on a given subject by adding several multimedia elements such as visual, audio and music to a scenario text in general (Banaszewski, 2005; Robin, 2006, 2008). Digital storytelling offers advantages such as providing diverse applications in the classroom environment, personalizing the learning experience, being interesting, helping difficult subjects explained, addressing real-life-related situations, supporting active learning, allowing for the creation of costless learning environments, and improving motivation and achievement (Gils, 2005; Hung, Hwang \& Huang, 2012; Robin, 2006; Suwardy, Pan \& Seow, 2013; Yang \& Wu, 2012). Robin (2008) states that digital storytelling helps students not only discuss the subjects given in the story but also organize the findings and concepts in a more understandable manner. Digital storytelling has the potential of facilitating the teaching and learning activities in the classroom setting (Xu, Park \& Baek, 2011; Yuksel, Robin \& McNeil 2011).

Most of the studies on digital storytelling emphasize that it is a powerful and effective instrument that can be used in educational environments (Karataş, Bozkurt \& Hava, 2016; Robin, 2006). Nevertheless, by whom the stories should be created needs to be specified before using digital storytelling in the classroom. There are several ways of using digital storytelling in education depending on how and at what stage the teacher will use it in the classroom environment. Developed by teachers based on the content of related course, digital stories can be utilized at separate times and in different situations with introduction, progress or conclusion activities in the classroom. In introduction activities, digital stories can be used for introducing the course, attracting attention, arousing curiosity and remind of pre-learning. With digital stories provided in progress activities, main concepts and principles of the course content can be brought to students by ensuring review, association, exemplification cooperation, observation, and monitoring. In the conclusion activities, it can be achieved that students reinforce the subject and become motivated for future learning by using digital stories for summarizing, integration, evaluation, feedback, correction, and remotivation for a course subject which is about to be concluded (Göçen, 2014).

Stories developed by teachers can be about experiences and events known to students (Suwardy, Pan \& Seow, 2013). These stories can be used for enriching the courses as a way for facilitating the discussion of the subject presented and making the abstract or conceptual content more comprehendible. Teachers can also benefit from digital stories they have created before as an instructional tool to attract students' attention to new ideas and teach a given subject in several disciplines (especially history, science or mathematics) (Robin, 2006, 2008). Digital stories prepared by students should be allowed in the learning process as well as the ones created by teachers. It is a key factor how students prepare and present their own digital stories under the guidance of teachers to take active role and learn by living in the instructional process (Göçen, 2014).

Technological instruction is achieved by several elements coming together. Undoubtedly, teachers are the most important component for ensuring that this process is realized in instructional environments successfully (Karakoyun, 2014). Some of the most important duties of teachers in this process include materializing a course such as mathematics which covers abstract concepts, ensuring using the learned information with stories and associating it with daily life, and performing activities to make learning environments enjoyable when learning and practicing by taking students away from the traditional understanding of instruction (Şahin, 1998 in Turgut \& Kışla, 2015). When storytelling is included in the mathematics instruction, students will learn to pay all their attention to learning as they are excited and have fun. It provides a motivating power when mathematical problems are given in a story-based context and meaningful manner and become realistic for children (Casey, 2004). Increasing number of teachers have been trying to make their students 'learning effective by integrating multimedia elements (picture, audio, video, etc.) with instructional materials (Robin, 2006). As digital storytelling has the potential of being an effective and useful educational instrument which combines innovative teaching-learning applications and digital media (Dakich, 2008), many teachers from preschool to higher education level have been wanting to use this instrument in their classrooms (Xu, Park \& Baek, 2011). As well as limited number of studies on digital storytelling in mathematics instruction and predominantly in preschool education in the literature (Casey 2004; Casey, Kersh \& Young 2004; Casey, Erkut, Ceder \& Young, 2008), it is seen that there are studies performed at secondary and high schools (Albano \& Pierri, 2014; Incikabi, 2015) and with teachers and preservice teachers (Gordon, 2011; İnan, 2015; Kildan \& Incikabi, 2015). Hence, it is thought to be important to include digital storytelling which facilitates explaining difficult concepts in a course such as mathematics that has abstract concepts by incorporating students in the learning process (Albano \& Pierri, 2014) in the courses. Based on the related considerations, this study aims to investigate the effects of mathematics courses instructed by association with digital storytelling on elementary school 8th-grade students' academic achievements and the teacher and student opinions on the application process. 


\section{Method}

The quasi-experimental method was used in the study. Before the application, the students were divided into the experimental and control groups according to their academic scores averages of mathematics. There were 30 students in the experimental group while the control group had 28 students.

\subsection{Participants of the Research}

The study group of the research was composed of 58 students who were attending two different classes of the 8th grade at a state secondary school and their mathematics teacher. The mathematics teacher has 14 years of experience in the profession and had a master's degree in the field.

\subsection{Application Process and Data Collection Instruments}

First, the digital stories to be used in the courses were prepared in this study aiming to examine the effects of mathematics courses that are associated with digital storytelling on elementary school 8th-grade students' academic achievements and the teacher and student opinions on the application process. Prior to the development process of the digital stories, interviews were performed with the mathematics teacher for preparing the activities to identify the grade level in which the application would be conducted and which learning objectives to be addressed. The teacher was informed of digital storytelling and four class hours of the teacher were observed in this process. As the learning objectives were suitable for digital storytelling and the teacher would instruct the subjects in the related order, it was decided in the interviews to prepare digital stories about the sub-learning domains of "Triangles", "Transformational Geometry" and "Probability of Simple Events" which are included in the mathematics curriculum (MEB, 2013). Moreover, the reason why this grade level was chosen is the idea that this application would help the 8th-grade students learn by having fun and motivate them because they were preparing for the exam for the transition from primary to secondary education exam (TEOG).

An Achievement Test was prepared by the researchers to identify the participant students 'knowledge levels regarding the subject prior to the application and measure their post-application achievements.

In the first preparation phase the Achievement Test, questions were prepared in consideration of the learning objectives in the related sub-learning domains of the mathematics curriculum. When examining these learning objectives, it was observed that they include phrases such as "building, drawing, forming an image, explanation" etc. and therefore it was decided that questions would be prepared as being open ended. 43 open-ended questions which were prepared in consideration of content validity were first reviewed by a Turkish instruction expert and the recommended corrections were evaluated by three field experts and applied to the questions without altering the mathematical content. A rubric was prepared for all questions. The pilot study for the 43 open-ended questions were conducted with 218 ninth-grade students attending 5 different high schools in Nigde province. The reason why it was conducted with the ninth-grade students is that they had learned the subjects in the test before. At the end of this pilot study, the best working questions were chosen in the same learning objective group depending on the item analysis results and a 14-question Achievement Test was formed. When choosing the questions, it was noted that the item discrimination index was above 0.40 and the item difficulty index was between 0.25 and 0.75 .

If the item difficulty index is close to 1.00 , the question is accepted as easy whereas it is accepted as moderate if it is about 0.50 and difficult if it is close to 0.00 . Items with an item discrimination index of 0.40 or higher are very good, those between 0.30 and 0.39 are quite good and those between 0.20 and 0.29 need to be corrected or improved. Items with 0.19 and lower item discrimination index are considered very poor and need to be omitted from the test (Karaca, 2008). While the difficulty indexes of the items in the Achievement Test vary between 0.10 and 0.91 , the item discrimination indexes vary between 0.10 and 0.85 . The reliability of the 43 -item test was calculated with the Cronbach- $\alpha$. Test's Cronbach- $\alpha$ reliability coefficient was found to be 0.906 . This coefficient found close to +1.00 means that the reliability is high. The analysis results of the final Achievement Test are shown in Table 1.

Table 1. Analysis Results of Pilot Study

\begin{tabular}{llllllll}
\hline N & Mean & SD & Median & Mode & $\begin{array}{l}\text { Average } \\
\text { Difficulty } \\
\text { Index }\end{array}$ & $\begin{array}{l}\text { Average } \\
\text { Discrimination } \\
\text { Index }\end{array}$ & $\begin{array}{l}\text { Reliability } \\
\text { (Cronbach's } \\
\text { Alpha) }\end{array}$ \\
\hline 218 & 20.119 & 8,821 & 21 & 21 & .468 & .493 & .906 \\
\hline
\end{tabular}

As seen in Table 1, the mean of the Achievement Test was found to be 20.119, its standard deviation 8.821 and average difficulty index .468 . The mean, median and mode being close to each other shows that the scores achieved in the Achievement Test were normally distributed. Furthermore, the skewness value of the data was found to be -.006 and the Kurtosis value -.814 . While these two values are 0 indicates that it is a normal distribution, a value between -1 and +1 shows that it does not significantly differ from the normal distribution. 
14 questions with each being for every learning objective of which item discrimination index is "very good" and "quite good" were chosen from 43 questions and a test form was created for the actual applications. The student answers obtained in the pilot study were examined and included in the rubric.

The answers were examined in four categories (totally correct, partly correct, incorrect and unanswered in the evaluation of the Achievement Test questions in the pretest, posttest and delayed-posttest (Akpınar \& Ergin, 2005; Bayram, Sökmen \& Savc1, 1997). Students' answers were graded 2 points (totally correct) if including all scientific explanations and correct ideas; 1 point (partly correct) if not the exact answer to the question but acceptable; 0 point (incorrect) if absent from scientific value and irrelevant to the question; and 0 point (unanswered) if repeating the whole or a part of the question or completely unanswered. The scores of each question in the Achievement Test were added, and the lowest score was calculated to be 0 and the highest score 28 .

The finalized Achievement Test was applied to the students who were attending two different classes of the 8th grade as a pretest. It was understood that there was no statistically significant difference between the score averages of the groups in the analysis of the Achievement Test scores.

The courses in the experimental and control groups were taught by the same teacher. There was no difference between the subjects instructed and instructional methods used by the teacher. The only difference between the groups along the application process was that the subjects were instructed in digital storytelling activities in the experimental group. In the control group, the courses were taught with the direct instruction that constantly in the courses where the mathematics teacher lectures the content theoretically and then asks exemplary questions and does test solutions. The students in the experimental group learned the same content with digital stories.

After the opinions of three experts, 11 digital stories were prepared for 14 learning objectives by the preservice teachers together with the mathematics teacher of the application classes and their peers who had received the same education were evaluated and adjusted. In addition, digital stories were applied by the mathematics teacher in different processes of the courses for four weeks. When developing the digital storytelling, seven elements of digital storytelling which the Center for Digital Storytelling recommends (Lambert, 2010; Robin, 2008) were considered. The literature was reviewed (Barrett, 2009; Jakes and Brennan, 2005; Kajder \& Swenson, 2004; Robin, 2008) and the steps to be taken were specified. Table 2 presents the titles of the digital stories developed for the learning domains.

Table 2. Digital storytelling activities developed for learning domains

\begin{tabular}{lll}
\hline Probability of Simple Events & Triangles & Transformational Geometry \\
\hline Ece and Kerem & Triangular Friends of Ela & Dream of Döndü \\
$\begin{array}{l}\text { Games of Chance } \\
\text { The Curious Emre and the World } \\
\text { of Probability }\end{array}$ & $\begin{array}{l}\text { The Teacher Ata } \\
\text { About Triangles with Karagöz and }\end{array}$ & $\begin{array}{l}\text { I'm Learning with my Elder Sister } \\
\text { Professor Arf } \\
\text { Keloglan and the Adventures }\end{array}$ \\
& \\
\hline
\end{tabular}

Students' opinions on the digital storytelling and the digital stories used in the course were received at the end of the course performed with digital storytelling in the learning environment. Semi-structured interviews were performed at the end of the application to find out about the opinions of the course teacher on digital storytelling and the application. Students' opinions were taken with the written opinion forms. Prior to the interviews, the literature was reviewed when preparing the questions and questions were specified in consideration of the research scope to see whether the students liked the courses performed with digital storytelling, which features they did and did not like and their thoughts about future applications. Other questions were prepared to see whether the course teacher found digital storytelling suitable for mathematics and teacher's opinions on the contribution of digital storytelling to the course and future applications. Three field experts were asked for opinions about the prepared questions and the questions were finalized upon the corrections in accordance with the suggestions.

After the application, the Achievement Test was applied to the experimental and control groups as a posttest and it was performed once again eight weeks after the application as a delayed-posttest to measure the retention of what had been learned.

\subsection{Data Analysis}

The SPSS software package was used in the study to analyze the quantitative data. Arithmetic means, standard deviations and t-test were utilized in the analysis of the quantitative data.

The qualitative data were subjected to a descriptive analysis. Regarding the demonstration of digital mathematical stories, opinions supporting the findings obtained in the interviews with the teacher were included in the study along with the descriptive analysis findings of the interview forms filled by all students. The data were summarized and 
interpreted by the themes specified prior to the application (Yıldırım \& Şimşek, 2006). During the data analysis, the students were encoded as S1, S2, S3, .... so that the they can be distinguished.

\section{Results}

This section comprises of the findings achieved in the Achievement Test applied to the groups and the findings about the opinions of the experimental group students and the mathematics teacher on digital storytelling and the application.

\subsection{Findings Obtained in the Achievement Test Applied to the Groups}

The Achievement Test was applied to the students in the experimental and control groups as a pretest, posttest and delayed-posttest to examine the effects of digital storytelling on students' academic achievements. The findings regarding the Achievement Test are shown in the tables below.

Table 3. T-test results of the achievement pretest scores by groups

\begin{tabular}{lllllll}
\hline Group & $\mathrm{N}$ & $X$ & $\mathrm{~S}$ & $\mathrm{sd}$ & $\mathrm{t}$ & $\mathrm{p}$ \\
\hline Experimental & 30 & 8.47 & 2.42 & 56 & .327 & .745 \\
Control & 28 & 8.68 & 2.53 & & & \\
\hline
\end{tabular}

No significant difference was found between the groups by the achievement pretest scores $\left.\underline{\left[t_{(56)}\right.}=.327, p>.05\right]$. According to Table 3, the mean of the control group students obtained in the achievement pretest is $X=8.68$ and the mean of the experimental group students obtained in the same test is $\bar{X}=8.47$. This finding indicates that there is no difference between the groups in regard to the levels of academic achievement.

Table 4. T-test results of the achievement posttest scores by groups

\begin{tabular}{lllllll}
\hline Group & $\mathrm{N}$ & $X$ & $\mathrm{~S}$ & $\mathrm{sd}$ & $\mathrm{t}$ & $\mathrm{p}$ \\
\hline Experimental & 30 & 17.77 & 5.17 & 56 & 1,342 & .185 \\
Control & 28 & 15.89 & 5.46 & & &
\end{tabular}

No significant difference was observed between the groups by the achievement posttest scores $\left[\mathrm{t}_{(56)}=1,342, p>.05\right]$. It is seen in Table 4 that the mean of the control group students obtained in the achievement posttest is $\bar{X}=15.89$ and the mean of the experimental group students obtained in the same test is $\bar{X}=17.77$. This finding shows that although there were no statistically significant differences between the groups in the posttest, the mean of the students in the experimental group were higher than the mean of the students in the control group.

Table 5. T-test results of the delayed-posttest scores by groups

\begin{tabular}{lllllll}
\hline Group & $\mathrm{N}$ & $X$ & $\mathrm{~S}$ & $\mathrm{sd}$ & $\mathrm{t}$ & $\mathrm{p}$ \\
\hline Experimental & 30 & 16.67 & 4.02 & 56 & 1,838 & .071 \\
Control & 28 & 14.35 & 5.48 & & &
\end{tabular}

It is understood from Table 5 that students' delayed-posttest scores did not significantly differ by the digital storytelling $\left[\mathrm{t}_{(56)}=1.838, \mathrm{p}>.05\right]$. The mean of the delayed-posttest in the control and experimental groups are 14.35 and 16.67 , respectively. Although there was no statistically significant difference between the groups, it is seen in Table 5 that score averages of the students in the experimental group were higher than the score averages of the students in the control group.

\subsection{Findings Obtained from the Student Opinions on Digital Storytelling}

The following findings were achieved in accordance with the analyses of the data regarding students'-opinions on the application process and digital storytelling.

Whether the students liked the course with digital storytelling was first asked to the students. 25 of them told they liked the course while 5 of them did not like it. Next, they were asked which features of the digital storytelling they liked during the application. It was understood that the students evaluated these features in terms of the use of digital stories in the mathematics courses and their contribution to students' learning. Student opinions on this topic are given in Table 6. 
Table 6. Features which the students did and did not like about the instruction of the course

\begin{tabular}{ll}
$\begin{array}{l}\text { Features which the students liked about the instruction } \\
\text { of the course }\end{array}$ & $\begin{array}{l}\text { Features which the students did not like about the } \\
\text { instruction of the course }\end{array}$ \\
\hline making the learning effective and fun & $\begin{array}{l}\text { being boring as a scenario was not suitable for the } \\
\text { level } \\
\text { simple and improper actions in a story } \\
\text { the voice speed was not sync with the story flow }\end{array}$ \\
$\begin{array}{l}\text { ensuring the permanent learning } \\
\text { facilitating the learning }\end{array}$ & $\begin{array}{l}\text { voice tone of the people who voiced the story was not } \\
\text { effective }\end{array}$ \\
$\begin{array}{l}\text { explaining the subject in a detailed, logical and clear } \\
\text { thay } \\
\text { having an effective material especially for subject were not addressed in a detailed and } \\
\text { repetition } \\
\text { being interesting }\end{array}$ & \\
$\begin{array}{l}\text { including visual elements } \\
\text { ensuring participation in the course }\end{array}$
\end{tabular}

The students stated that they liked the following features of the course instructed with digital storytelling: "making the learning effective and fun" (17 students), "including real-life examples" (9 students), "ensuring the permanent learning" (7 students), "facilitating the learning" (5 students), "explaining the subject in a detailed, logical and clear way" (4 students), "having an effective material especially for subject repetition" (3 students), "being interesting" (3 students), "including visual elements" ( 2 students), and "ensuring participation in the course" ( 2 students). The students provided the following thoughts about the topic:

"How they are retentive... When there is storytelling, it is both fun and instructive." (S24)

"[E]specially the triangles. I haven't understood the triangles clearly before. But I've understood more clearly now." (S5)

"Ata the Teacher and Emre the Curious and the World of Probability contribute to my learning. Because it was fun and logical." (S14)

" [I]t was prepared with care. All was effective and fun." (S20)

"They are examples from daily life..." (S13)

"The information is more retentive in general when it is given visually. That's why I think it's a good activity." (S9)

"The subjects are more retentive and the course becomes more fun with digital storytelling..." (S27)

"[I]t was more retentive than the course instruction." (S28)

"[A]s it is a better way to instruct the course with storytelling, I understood the subjects I didn't(elements of triangle) better." (S16)

"[A]ll of them, maybe. Because it's a good method for attracting the attention of those who aren't interested in the course." (S19)

S13 and S30, unlike their peers, expressed how digital storytelling contributed to the course in the following statements:

"Yes. Because everyone focuses on the story and doesn't speak in the classroom..." (S13)

"Yes, I want that. Because not all my friends listen to the teacher in normal courses. But everyone focused and it was more enjoyable when it was instructed by this way." (S30)

It was found that the features which the students did not like about the digital storytelling in the course were diverse and most of them were "being boring as a scenario was not suitable for the level" (6 students) and "simple and improper actions in a story" (3 students). Opinions of the students regarding this finding are as follows:

"[E]ce and Kerem was a boring story because it wasn't suitable for our age group. Because the scenario wasn't creative." (S 11)

"All was nice but I got bored with Ece and Kerem a bit. I'd liked it, too if it'd been prepared for my level but it was so simple for me." (S30) 
Alongside these features, some of the students stated that they did not like it because "the voice speed was not sync with the story flow" (3 students), "voice tone of the people who voiced the story was not effective" (2 students), and "the subjects were not addressed in a detailed and extensive way as a whole" (2 students).

" [A] t one point of one of the stories related to transformational geometry, voices weren't sync with the speeches. That's why I got a bit distracted and couldn't focus. I had trouble with understanding but I understood later."(S7)

"The voice actors and the actors in Ece and Kerem felt pretended, they weren't professional enough. Storytelling would've been more active if the acting and voicing had been of quality..." (S11)

As understood from the student opinions, most of the features which the students did not like were for one story (Ece and Kerem). Another story (I'm Learning with my Elder Sister) did not attract students' attention as it the voice speed and the story follow were not sync for a moment. How 14 students reported that there were no features that they did not like about the application was among the remarkable findings of the study.

As for student opinions on the applications in future courses, majority (20 students) of them stated that they want this application to continue in future mathematics courses. The student opinions regarding this topic are as follows:

"Yes, I want that. Because information is conveyed in a more enjoyable way and this contribute to our comprehension." (S3)

"Yes, I'd want that. Because we'd understand the subjects better and reinforce that subject more properly and better because real-life events are cited and exemplified. So, I'd want that to be instructed." (S16)

"Yes. By giving examples, I saw the examples from our daily life and it was more retentive." (S23)

"Yes, because it's a method which is very fun and ensure permanent learning." (S28)

Some of the students ( 5 students) stated that they do not want the courses to be instructed with digital storytelling in the future. The students justified their opinion by reporting that they think traditional courses instructed with question-answer at the whiteboard are more effective (4 students), everyone may not understand the storytelling presented with music and visuals, therefore some students can understand what is verbally narrated ( 2 students), and they had difficulty to get accustomed to the method even if these studies are enjoyable because it is different than other methods which have been used in the courses for years. S26 explained why he/she does not want the digital stories to be used in future courses because he/she thinks teachers may have the students prepare the digital stories in the next step:

"No, because our mathematics teacher would probably have us do it as a project and I wouldn't like others to see what I do..." (S26)

9 students stated that they want digital storytelling to be used occasionally as it is not suitable for every subject and every stage of the mathematics course. The following is the opinions of S27 and S29 on the subject:

"If there is a mathematics course for 6 hours a week, only one course should be instructed this way. It might get boring if every course was instructed like this." (S27)

"It may in some courses if not always. This way, we can both learn and rehearse the subject and have fun." (S29)

\subsection{Findings Obtained from Opinions of the Mathematics Teacher on Digital Storytelling}

In the semi-structured interview performed with the mathematics teacher, firstly, it was asked whether the teacher had knowledge of digital storytelling before and what his/her opinions on the use of digital stories in the mathematics course. The teacher stated that he/she did not any knowledge of digital storytelling and provided the following statements about his/her opinions on the process:

“It's an appropriate method for the mathematics course. I haven't thought it'd attract students' attention this much in the beginning... However, it is certainly important that scenarios being suitable for the grade levels. Such a storytelling method is more suitable for and applicable to other grades... Is it suitable for every subject? It could be used when giving the learning objectives in the subject, but no, when looking at it as a whole. Stories would be very long for the whole subject; it becomes boring especially for mathematics. Lower grades than the 7th grade, for example, it can be applied to the 5th-grade easily. It can attract their attention much more... These stories can be prepared by the students to provide more contribution to mathematics as a course. Therefore, their knowledge and skills about the course increases and they become more willing... But unfortunately, we don't have time for that."

It is understood from the teacher statements that digital storytelling drew students' attention and the teacher thought of its use in mathematics courses positively. The teacher also emphasized the importance that scenarios should be prepared in consideration of the grade level and digital storytelling is not appropriate when giving the whole subject. In addition, the teacher added that he/she thinks scenarios prepared by students would contribute to a more effective instruction so that students could be more active in the process but it is hard to spare time for these applications. 
As for the teacher opinion on what benefits digital storytelling has in terms of instruction, the teacher stated that its most important benefit is being attention-grabbing. He/she also mentioned that it provides participation in course and learning by having fun as it increases students' academic achievements and motivations. The teacher opinion regarding this topic is as follows:

"Advantages of storytelling is being attention-grabbing and sufficient for presenting the learning objective. It ensures learning by having fun, which I think is important for the mathematics course... motivation would increase and students would be more enthusiastic about participating in the course. Effective instruction could be performed with well-prepared stories, therefore increasing students' achievement in the course. Information could be provided and feedback could be received because it reinforces the subject with questions..."

When asked about his/her opinions and recommendations on the use of digital storytelling in future instructions, the teacher provided the opinions below about how the process of preparing stories is primarily difficult and time-taking:

"Preparing stories is an issue to be very careful with, difficult and time-consuming. Because it doesn't mean that it would teach well just because there is music and fun; one should pay attention... Scenario would waste time if it was boring and wasn't attention-grabbing. In this case, students would get distracted and bored... If it was well-prepared, it would help them understand the subject better; students would learn willingly, therefore associating with the life more easily..."

The teacher also stated that he/she do not have enough time to prepare digital stories or have students prepare them and would need the support of an expert even if he/she wanted to do it; however, he/she could use them if digital stories developed in accordance with the subjects and learning objectives were readily available. The following is the opinions of the teacher on the topic:

"[A]s I mentioned before, we don't have the time to spare for it. In fact, our students might prepare them, too. Some of them might even create better stories... But I'd need help for this in the first place. There is a computer laboratory in the school... Maybe an expert; I mean, expert's help is necessary so I can learn. Kids know about technology more than us under today's circumstances. They'd not have trouble with it much. But when students or I would prepare it, what can I say? This is about our educational system and the expectations of administrators and parents. As students, especially the 7th and 8th grade students have TEOG exams ahead, we're using the smart whiteboard only when we're solving questions to save time. Time is crucial to us. But if we didn't have the time problem and students prepared it, it could be applied on all grade levels including the 7th and 8th grades... Yet, I could only use the stories which are readily available like the ones in this instruction.

It is understood from the statements above that the teacher thinks it would contradict the expectations of administrators and parents if he/she wanted students to prepare the digital stories because they are preparing for the TEOG exam.

\section{Discussion}

Storytelling has been used as a natural and powerful instrument to date for sharing information, values and experiences (Smeda, Dakich \& Sharda, 2014). It is also a popular instrument used in every domain of natural and social interaction for human communication and commonly used in classrooms to enrich the learning experience. Digital storytelling is an effective technological tool of education used in classrooms to enhance teaching and learning (Robin, 2006; Suwardy, Pan \& Seow, 2013; Xu, Park \& Baek, 2011).

The Achievement Test was applied to the students in the experimental and control groups as a pretest, posttest and delayed-posttest to examine the effects of digital storytelling on students' academic achievements. It was found that even though posttest and delayed-posttest score averages of the experimental group students were higher than the score averages of the control group students, there was no significant difference between their Achievement Test scores. This can be explained by the fact that the students both in the experimental and control groups had studied the related subjects during the preparation period for the TEOG exam. Indeed, Şad and Şahiner (2016) found in their study that the participants thought the examination system bring methodical studying habits and would affect the student achievement positively. Differently from this result achieved in the study, there are several studies concluding that digital storytelling has a positive impact on student achievements (Göçen, 2014; Hung, Hwang \& Huang, 2012; Kahraman, 2013; Yang \& $\mathrm{Wu}, 2012$ ). In the experimental study conducted by Göçen (2014) which aimed to examine the effects of learning based on digital storytelling method on students' academic achievements and learning and studying strategies, instruction based on digital storytelling was applied to the experimental group while PowerPoint presentation-assisted instruction was applied to the control group. It was concluded that digital storytelling method was more effective in increasing academic achievement and the use of learning and studying strategies than the PowerPoint presentation-assisted instruction. It was found in the quasi-experimental study performed by Hung, Hwang and Huang (2012) with the 5 th-grade students in the science class that project-based digital scenario activities improved students' science learning 
motivation, problem-solving proficiency and learning achievements efficiently. Similarly, the study in which Yang and $\mathrm{Wu}$ (2012) aimed to investigate the effect of digital storytelling on the academic achievement, critical thinking and learning motivation of advanced high school students who were learning English as a foreign language showed that digital storytelling participants significantly performed better than other participants in terms of English achievement.

At the end of the application in this study, it was understood that majority of the students liked the mathematics courses instructed with digital storytelling and wanted the use of digital storytelling to continue in future courses. This result parallel with the results achieved in the study by Smeda, Dakich and Sharda (2014).

Much as the features which majority of the students liked about the digital storytelling during the instruction with digital stories varied, it was found that they mostly emphasized the features of making the learning effective and fun, ensuring association with daily life, ensuring the permanent learning and facilitating the learning. In addition, some of the students stated they liked the digital stories because they were attention-grabbing, included visual elements, narrating the subject in a detailed, logical and straightforward way and ensured participation in the course. How the course teacher also found the storytelling to be interesting, effective, ensuring the learning by having fun, increasing the motivation and achievement, ensuring the meaningful learning and facilitating association with daily life indicates the compliance of the provided answers. The study conducted by Karataş, Bozkurt and Hava (2016) with history teachers also conclude that digital storytelling had benefits such as being interesting, facilitating the learning and ensuring the permanent and active learning. İnan (2015), Smeda, Dakich and Sharda (2014), Kahraman (2013) and Gils (2005) emphasized in their studies how digital storytelling is interesting and enjoyable, too. Similarly, the students in the studies performed by Wang and Zhan (2010) and Karakoyun (2014) reported that digital storytelling activities were fun in general. Yüksel, Robin and McNeil (2011) and Xu, Park and Baek (2011) stated that digital storytelling activities reinforce easy and permanent learning. It is highlighted in the literature that digital storytelling activities help incorporate real-life situations (Di Blas, Garzotto, Paolini \& Sabiescu, 2009; Gils, 2005; Göçen, 2014; Kocaman-Karaoğlu, 2015; McLellan, 2006; Suwardy, Pan \& Seow, 2013; Woodhouse, 2008). In the study conducted by Sadik (2008), the teachers stated that digital storytelling helped students have a better understanding of the subjects in the program better.

Some of the students stated that the stories are effective materials for the rehearsal of the subject. Similarly, the result achieved by Karataş, Bozkurt and Hava (2016) that using the digital stories in the instructional environment might be useful for presenting the subject in summary is parallel with this result of the study. Robin (2007) states that digital storytelling is a powerful learning and teaching instrument that enables participation in all domains. In this study, it was remarkable that two students and the mathematics teacher thought it ensured participation in the course. The finding in the study performed by Kahraman (2013) that the students thought digital stories increased the participation in the course same with the results of this study.

Turgut and Kışla (2015) stated that stories need to be well-structured so that they can be effective and recalled. Whereas Banaszewski (2005) emphasized that the digital story creation process requires specialty in preparing scenarios, dubbing, and being a visual and media literate, Demirer (2013) drew attention to the importance of using the audial elements effectively in a good digital story and dubbing is a step that makes the story stronger. As for the student opinions on the features of stories used in the courses which they did not like, they emphasized that especially one scenario was boring because it was not suitable for the level. Other features which the students did not like include how actions were simple and improper, the voice speed and the story flow were not in sync in one story, the voice tone of the people who voiced the story was not effective and the subjects were not addressed in a detailed and extensive way. The course teacher drew attention to the fact that digital stories should be suitable for the level, stories should be well-planned and prepared, and storytelling would be long and boring if it were prepared for the whole subject shows parallelism with the students' opinions. Robin (2006) stated that a bad scenario for storytelling might affect the digital storytelling process in a negative way as the multimedia elements used in digital storytelling and voicing of the story ensure the content to be understood by helping listeners personalize the story. According to Oppermann (2007), a well-prepared story is generally found by unwilling students with low motivation attention-grabbing. Göçen (2014) mentioned that digital stories need to be planned with methods and techniques suitable for the age level of the group.

It was found regarding the student opinions on the applications in future courses, majority of them stated that they want this application to continue in future mathematics courses. Woodhouse (2008) stated that digital storytelling may not be suitable for the learning of every individual. In this study, it was observed as for the opinions of the students who does not want this method that they think digital storytelling is not suitable for their learning. Some of the students mentioned that they find the courses instructed with question-answer which they are accustomed to more productive. This can be explained by the fact that they want to solve more questions because they are preparing for the TEOG exam. Moreover, some of the students stated that they want digital storytelling to be used occasionally as it is not suitable for every subject and every stage of the mathematics course. Indeed, the course teacher reported that time is very important 
to them as the students are preparing for the TEOG exam and he/she is using the technology only to speed up the question solving. Differently from the result of this study, in the study performed by Dogan and Robin (2008), majority of the teachers thought that digital storytelling could be used as an effective instructional tool to prepare students for standardized tests such as Texas Assessment of Knowledge and Skills (TAKS).

When the course teacher was asked about whether to use digital storytelling in future instructions, he/she could not spare time for preparing stories or having students prepare them as the preparation process is hard and time-consuming, expert support is needed for application and because of the expectations of the educational system; however, he/she added that storytelling prepared suitably for subjects and learning objectives could be utilized. When examining the related literatures, it is seen that preparing the digital stories is time-consuming (Dogan \& Robin, 2008; Duveskog, Tedre, Sedano \& Sutien, 2012; İnan, 2015; Robin, 2006; Sadik, 2008; Woodhouse, 2008) and technical support is required for the use of digital stories at schools (Assan \& Thomas, 2012; Çakır \& Y1ldırım, 2009; Dogan \& Robin, 2008; Ertner, 1999; Y1lmaz, 2011). In Robin and McNeil's (2013) study, some of the teachers stated that they need to be trained about how to create and use digital storytelling. Similarly, Karakoyun (2014) stated that teachers should be trained about the use of digital storytelling further as it is a new educational technology instrument. Lin and $\mathrm{Lu}(2010)$ states that teachers need to have training on the technological instruction in the classroom and the use of certain technological instruments. Unlike this result of the study, it was observed at the end of the study conducted by Dogan and Robin (2008), majority of the teachers chose their own stories over the ones created by others.

It is also seen in this study that majority of the students want digital stories to continue to be used in mathematics courses and the mathematics teacher think learning would be more effective if digital stories were prepared by students. Similarly, Dogan and Robin (2008) concluded that majority of the students wanted their teachers to use more digital storytelling in the classroom, and moreover, many students wanted their teachers to allow them to use more digital stories in their classrooms.

Consequently, although there were no statistically significant differences between the groups in their pretest, posttest and delayed-posttest score averages, score averages of the students in the experimental group were found to be higher in the posttest and delayed-posttest score averages than the score averages of the students in the control group. This result shows parallelism with other studies in the literature (Demirer, 2013; Gordon, 2011; İnan, 2015; Sadik, 2008; Smeda, Dakich \& Sharda, 2014; Suwardy, Pan \& Seow, 2013). The results achieved in this study show that digital storytelling is a powerful instrument to create more interesting and enjoyable learning environments which facilitate association with daily life, allow for effective learning and participation. Hence, digital storytelling activities and studies can be made more common in abstract courses including mathematics. A short-term application was performed in this study. It is thought that longer-term studies with more digital mathematical stories would be more effective. It was explored in this research that digital storytelling activities are not very easy for teachers and infrastructure and expert support should be provided. It is therefore necessary to bring required knowledge and skills to teachers and provide technical infrastructure and expert support. Some of the students in the study found one of the digital storytelling scenarios not suitable for the age level and boring. Therefore, digital stories can be developed in accordance with the opinions received from students and their interests and wishes in future studies. Digital stories prepared by others were also utilized in the research. It is mentioned in the literature that digital storytelling helps students participate in the learning process more actively than teachers and reinforce the student-centered instruction (Xu, Park \& Baek, 2011). Hence, it is obvious that digital stories would be more useful if developed by students. Based on these considerations, studies need to be conducted to enable students to prepare digital stories with necessary precautions for a result in success and in consideration of various elements (technological infrastructure and technical support, time, etc.)

\section{References}

Akpınar, E., \& Ergin, Ö. (2005). An application on the science teaching based on the constructivist theory. Hacettepe University Faculty of Education Journal, 29(29).

Albano, G., \& Pierri, A. (2014). Digital storytelling for improving mathematical literacy. In S. Carreira, N. Amado, K. Jones \& H. Jacinto (Eds), Proceedings of the Problem@Web International Conference: Technology, Creativity and Affect İn Mathematical Problem Solving (pp. 23-34). Faro: Universidade do Algarve.

Assan, T., \& Thomas, R. (2012). Information and communication technology Integration into teaching and learning: Opportunities and challenges for commerce educators in South Africa. International Journal of Education and Development using Information and Communication Technology, 8(2), 4-16.

Banaszewski, M. T. (2005). Digital storytelling: Supporting digital literacy in grades 4-12. Unpublished Master's Thesis, Georgia Institute of Technology. Accessed at http://hdl.handle.net/1853/6966 on 11.03.2017

Barrett, H. (2009). How to create simple digital stories. Accessed at 
http://electronicportfolios.com/digistory/howto.htmlon 12.02.2017

Bayram, H., Sökmen, N., \& Savc1, H. (1997). Identifying the readability of the basic concepts of sciences. M. U. Atatürk Faculty of Education, Journal of Educational Sciences, 9, 89-100.

Çakır, R., \& Yildirim, S. (2009). What do computer teachers think about the factors affecting technology integration in schools. İlköğretim Online, 8(3), 952-964.

Casey, B. (2004). Mathematics problem-solving adventures: A language-arts-based supplementary series for early childhood that focuses on spatial sense. In D. H. Clements, J. Sarama \& A.-M. DiBiase (Eds.), Engaging young children in mathematics: Standards for early childhood mathematics education (pp. 377-389). Mahwah, NJ: Lawrence Erlbaum Associates, Publishers.

Casey, B., Erkut, S., Ceder, I., \& Young, J. M. (2008). Use of a storytelling context to improve girls' and boys' geometry skills in kindergarten. Journal of Applied Developmental Psychology,29(1), 29-48. https://doi.org/10.1016/j.appdev.2007.10.005

Casey, B., Kersh, J. E., \& Young, J. M. (2004). Storytelling sagas: An effective medium for teaching early childhood mathematics. Early Childhood Research Quarterly, 19(1), 167-172. https://doi.org/10.1016/j.ecresq.2004.01.011

Condy, J., Chigona, A., Gachago, D., \& Ivala, E. (2012). Pre-service students' perceptions and experiences of digital storytelling in diverse classrooms. TOJET: The Turkish Online Journal of Educational Technology, 11(3), 278-285.

Dakich, E. (2008). Towards the social practice of digital pedagogies. In N. Yelland, G. Neal \& E. Dakich (eds.), Rethinking education with ICT: New directions for effective practices, pp. 13-30. Sense Publishers, Rotterdam and Taipei.

Demirer, V. (2013). Use and effects of e-storytelling in elementary education. Unpublished Master's Thesis, Necmettin Erbakan University, Institute of Educational Sciences, Konya.

Di Blas, N., Garzotto, F., Paolini, P., \& Sabiescu, A. (2009, December). Digital storytelling as a whole-class learning activity: Lessons from a three-years project. In Joint International Conference on Interactive Digital Storytelling (pp. 14-25). Springer Berlin Heidelberg. https://doi.org/10.1007/978-3-642-10643-9_5

Dogan, B., \& Robin, B. (2008). Implementation of digital storytelling in the classroom by teachers trained in a digital storytelling workshop. K. McFerrin et al. (Ed.), Proceedings of Society for Information Technology \& Teacher Education International Conference 2008 (p. 902-907). Chesapeake, VA: AACE.

Duveskog, M., Tedre, M., Sedano, C. I., \& Sutinen, E. (2012). Life planning by digital storytelling in a primary school in Rural Tanzania. Educational Technology \& Society, 15(4), 225-237.

Ertmer, P. A. (1999). Addressing first-and second-order barriers to change: Strategies for technology integration. Educational technology research and development, 47(4), 47-61. https://doi.org/10.1007/BF02299597

Gils, F. (2005, June). Potential applications of digital storytelling in education. In 3rd Twente Student Conference on IT (Vol. 7). University of Twente, Faculty of Electrical Engineering, Mathematics and Computer Science Enschede.

Göçen, G. (2014). Effects of digital storytelling method on students' academic achievement and strategies of learning and studying. Unpublished Master's Thesis, Muğla Sitkı Koçman University, Institute of Educational Sciences, Muğla.

Gordon, C. (2011). Digital Storytelling in the Classroom: Three case studies. (Unpublished doctoral dissertation). Arizona State University. Retrieved from ProQuest Digital Dissertations. (UMI 3487362)

Hung, C. M., Hwang, G. J., \& Huang, I. (2012). A Project-based digital storytelling approach for improving students' learning motivation, problem-solving competence and learning achievement. Educational Technology \& Society, 15(4), 368-379.

Inan, C. (2015). A digital storytelling study project on mathematics course with preschool pre-service teachers. Educational Research and Reviews, 10(10), 1476-1479. https://doi.org/10.5897/ERR2015.2247

Incikabi, L. (2015). Teaching history of mathematics through digital stories: A technology integration model. Handbook of research on educational technology integration and active learning, 162-176. https://doi.org/10.4018/978-1-4666-8363-1.ch008

Jakes, D. S., \& Brennan, J. (2005). Capturing stories, capturing lives: An Introduction to digital storytelling. Accessed at http://bookstoread.com/etp/earle.pdf on 10.03.2017

Kahraman, Ö. (2013). Use of materials prepared with digital storytelling method in the introduction phase of learning 
cycle on the physics course achievement and motivation level. Unpublished Master's Thesis, Balıkesir University, Institute of Science, Balıkesir.

Kajder, S. B., \& Swenson, J. A. (2004). Digital images in the language arts classroom [Electronic version]. Learning and Leading with Technology, 31(8), 18-19.

Karaca, E. (2008). Test and item analysis. In (ed. S. Erkan and M. Gömleksiz), Assessment and measurement in educaţ̧ın (p. 239-306). Ankara: Nobel.

Karakoyun, F. (2014). An examination of preservice teachers' and elementary school students'opinions on the digital storytelling activities created in the online setting. Unpublished Master's Thesis, Anadolu University, Institute of Educational Sciences, Eskişehir.

Karataş, S., Bozkurt, Ş. B., \& Hava, K. (2016). The perspective of history preservice teachers towards the use of digital storytelling in educational environments. Journal of Human Sciences, 13(1), 500-509. https://doi.org/10.14687/ijhs.v13i1.3167

Kildan, A. O., \& Incikabi, L. (2015). Effects on the technological pedagogical content knowledge of early childhood teacher candidates using digital storytelling to teach mathematics. Education 3-13, 43(3), 238-248. https://doi.org/10.1080/03004279.2013.804852

Kocaman-Karaoğlu, A. (2015). Storytelling's nature changed with technology in the instructional process: Digital storytelling. Education Technology Theory and Application, 5(2), 89-106.

Lambert, J. (2010). Digital storytelling cookbook and traveling companion. Berkeley, CA: Digital Diner Press.

Lin, C., \& Lu, M. (2010). The study of teachers' task values and self-efficacy on their commitment and effectiveness for technology-instruction integration. US-China Education Review, 7(5), 1-11.

McLellan, H. (2006). Digital storytelling in higher education. Journal of Computing in Higher Education, 19(1), 65-79. https://doi.org/10.1007/BF03033420

MEB (2013). Secondary education (5th-8th grades) mathematics curriculum, Ankara: MEB Directorate of Education Press.

Oppermann, M. (2007) Writing in 'that other space': digital storytelling and the scholarship of teaching in American studies, Teaching American Studies in the Twenty-First Century, 52(3), 22-28.

Robin, B. (2006). The educational uses of digital storytelling. C. Crawford et al. (Ed.), Proceedings of Society for Information Technology \& Teacher Education International Conference (pp. 709-716). Chesapeake, VA: AACE.

Robin, B. (2007). The convergence of digital storytelling and popular culture in graduate education. R. Carlsen et al. (Ed.). Proceedings of Society for Information Technology \&Teacher Education International Conference (pp. 643-650). Chesapeake, VA: AACE.

Robin, B. (2008). Digital storytelling: A powerful technology tool for the 21st century classroom. Theory into Practice, 47, 220-228. https://doi.org/10.1080/00405840802153916

Robin, B., \& McNeil, S. (2013). The evolution of digital storytelling technologies: From PCs to iPads and e-Books. R. McBride \& M. Searson (Ed.), Proceedings of Society for Information Technology \& Teacher Education International Conference (s. 1712-1720). Association for the Advancement of Computing in Education (AACE).

Şad, S. N., \& Şahiner, Y. K. (2016). Student, teacher and parent opinions on the system of Transition from Primary to Secondary Education (TEOG). Illkögretim Online, 15(1).

Sadik, A. (2008). Digital storytelling: A meaningful technology-integrated approach for engaged student learning. Educational Technology Research and Development, 56, 487-506. https://doi.org/10.1007/s11423-008-9091-8

Smeda, N., Dakich, E., \& Sharda, N. (2014). The effectiveness of digital storytelling in the classrooms: a comprehensive study. Smart Learning Environments, 1(1), 6. https://doi.org/10.1186/s40561-014-0006-3

Suwardy, T., Pan, G., \& Seow, P. S. (2013). Using digital storytelling to engage student learning, Accounting Education, 22(2), 109-124. https://doi.org/10.1080/09639284.2012.748505

Turgut, G., \& Kışla, T. (2015). The use of computer-aided story in education: literature review. Turkish Online Journal of Qualitative Inquiry, 6(2), 97-121. https://doi.org/10.17569/tojqi.57305

Wang, S., \& Zhan, H. (2010). Enhancing teaching and learning with digital storytelling. International Journal of Information and Communication Technology Education (IJICTE), 6(2), 76-87.

https://doi.org/10.4018/jicte.2010040107 
Woodhouse, J. (2008, June). Story-telling: A telling approach in healthcare education. Paper presented at the Narrative Practitioner Conference, Wrexham, UK.

Xu, Y., Park, H., \& Baek, Y. (2011). A new approach toward digital storytelling: An activity focused on writing self-efficacy in a virtual learning environment. Educational Technology \& Society, 14(4), 181-191.

Yang, Y. T. C., \& Wu, W. C. I. (2012). Digital storytelling for enhancing student academic achievement, critical thinking, and learning motivation. A year-long experimental study. Computers \& Education, 59(2), 339-352. https://doi.org/10.1016/j.compedu.2011.12.012

Yıldırım, A., \& Şimşek, H. (2006). Qualitative research methods in social sciences. Ankara: Seçkin Yayıncılık.

Yilmaz, N. P. (2011). Evaluation of the technology integration process in the Turkish education system. Contemporary Educational Technology, 2(1), 37-54.

Yuksel, P., Robin, B., \& McNeil, S. (2011). Educational uses of digital storytelling all around the world. M. Koehler \& P. Mishra (Ed.), Proceedings of Society for Information Technology \& Teacher Education International Conference (pp. 1264-1271). Chesapeake, VA: AACE.

\section{Copyrights}

Copyright for this article is retained by the author(s), with first publication rights granted to the journal.

This is an open-access article distributed under the terms and conditions of the Creative Commons Attribution license which permits unrestricted use, distribution, and reproduction in any medium, provided the original work is properly cited. 